\title{
Functional Expert-based Performance Assessment Models at Organizational Level
}

\author{
Emad Elwakil ${ }^{1 *}$
}

\begin{abstract}
Organizations performance assessment is one of the critical aspects in today's project management research. The performance of organizations can be affected by various factors beyond financial measures. Construction organizations faces difficulty in performance assessment stemming from the uncertain fragmented unique nature of the construction industry. Only few research focused on the non-financial factors that impact the organizations performance. Although many research works have been done to study organization success factors, most of the conducted research was only focusing on the construction project level rather than the organizational level. In addition, most of the research neglected the different perspectives of construction organizations functional units when assessing the performance. The goal of this research is to study the effect of different functional units on the company performance through identifying, ranking a set of critical success factors (CSFs) and build comprehensive performance construction organizations assessment models. Analytical Hierarchy Process (AHP) technique has been used for the data analysis and the models' development. The research findings indicated that the CSFs factors in construction organizations have different priorities and weights according to the different functional units. Four assessment models are eventually developed to reflect the unique perspective of four functional units in construction organizations. The developed models have been validated with satisfactory results ranging $80 \%$ to $90 \%$. This research will benefit organizations managers to accurately assess their performance according to the different functional units.
\end{abstract}

\section{Keywords}

Organizational Performance; Performance Assessment Models; Organizational Functional Units, Analytical Hierarchy Process (AHP)

${ }^{1}$ School of Construction Management, Purdue University, West Lafayette, IN, 47907, USA, email: eelwakil@purdue.edu (corresponding author)

The Engineering Project Organization Journal

(C)2017 Engineering Project Organization Society www.epossociety.org 
Modeling the performance of construction

\section{Introduction}

Organization performance assessment is a crucial to any organization in today's market as performance is the main driver for success and profit. Moreover, it is even more challenging to maintain that strategy in construction organizations because of the complexity and fragmented nature of construction organizations (Abraham, 2002). To achieve success, construction organizations must fully understand the factors that affect the organizations' performance (Kaplan and Norton, 1995) as well as the diversity in the perception of those success factors between the different functional units within the same organization. Critical Success Factors (CSFs) evaluation is the most appropriate methodology to assess as evaluate the organizations performance in order to achieve their main goals of developing a comprehensive monitoring system that contains corporate-wide indicators of success (Holohan, 1992).

Construction is a diverse, project-based industry (Ozorhon, 2012). The project-based nature of the construction industry makes every project unique (Veshosky, 1998). Moreover, the market structure is extremely fragmented, making it very competitive and difficult for any particular organization to dominate (Kim \& Reinschmidt, 2012). The unique nature of concerns and challenges often render the generalizable decision rules and frameworks for organizational phenomena unusable (Pinto \& Covin, 1989). Financial and tangible assets gained are often translated to organization success. In a review of project success factors conducted, it has been noted that project success was considered only as a subject of implementation in the 1980s (Muller, 2012).

Although many research works have been done to study organization success factors, most of the conducted research was only focusing on the construction project level rather than the organizational level (Abraham 2002; Elwakil et al. 2009; Zayed et al. 2012; Barakat et al. 2015; Hu et al. 2016; Mao et al. 2016; Lichtenthaler, 2016; Bevilacqua et al. 2017; Connelly et al. 2017; Martinez-Conesa et al. 2017; Böhm et al. 2017; Li et al. 2017). organizations from a financial prospective has been extensively researched; however, modeling the performance considering non-financial aspects has not receive sufficient attention from researchers (Rathore, 2016).

\section{Research Objectives}

The main objectives of this research are to study the differences between functional units' perspectives in construction organizations, and how these differences affect the construction organizations performance. The objectives can be broken down into the following sub-objectives:

- Determine the impact of the critical success factors on the organization performance.

- Build functional units based assessment models for construction organizations.

\section{Background}

Construction organizations' success definition has been evolving over the past decade, it is mostly defined as the overall achievement of the organization's goals and expectations. Moreover, success can be assessed differently from individual to another according to their perspective. Elwakil et al. (2009) determined 18 most significant success factors for performance assessment of construction organizations. A regression model has been developed to assess construction organizations performance. The obtained data was analyzed using back propagation model of artificial neural networks (ANN), which was used to determine the relative significance of various success factors. After specifying the critical success factor, an ANN organization performance model was developed. Zayed et al. (2012) identified factors CSFs to be the most significant to develop an assessment model for organizational performance. Artificial neural network (ANN) model was used to assess the most significant success factors, as ANN provides the contributing weight of each factor after the completing of the training process. However, there is a lack of research on assessment of construction 
organizations based performance. Moreover, the existing research does not take into consideration the different perspectives of the different functional units. It does not consider how the different units perceive the success factors differently, and thus can affect the performance assessment. The previous models have neglected the qualitative variables which have been considered as a disadvantage of expert opinion. Critical Success Factors are defined by (Rockart, 1978) as the critical areas where high performance or success is important, as they decide the success of an organization. CSFs are the actual steps taken to succeed. Special attention and concern should normally be given to those areas, as those areas can decide the present and the future success of the organization based on its performance (Boynton and Zmud, 1984). For the purpose of this research, 18 critical success factors were identified as the factors that impacts construction organizations success. (Elwakil et al., 2009, Zayed et al., 2012) classified those factors as the following:

1. Administrative \& legal factors group includes the sub-factors: clear vision, mission \& goals, competition strategy, organizational structure, political conditions, and number of full time employees.

2. Technical factors group includes the subfactors: usage of international aspects, availability of knowledge, usage of it, business experience (no. of years), and product maintenance.

3. Management factors group includes the sub-factors: employee culture environment, employee compensation and motivation, applying total quality management, and training.

4. Market \& finance factors group includes the sub-factors: quick liquid assets, feedback evaluation, research \& development, and market conditions/customer engagement.

Tsiga et al. (2016) identified 58 success factors that were then classified into 11 groups. These factors were then tested within the space industry using an elicitation technique, using the relative importance index approach to rank the classified categories based on their perceived importance. Babatunde and Zhou (2016) used the critical success factors (CSFs) to develop a process maturity and determine the current maturity levels of stakeholder organizations in public-private partnership (PPP). The study found that the maturity of CSFs made PPP projects successful. Wibowo and Alfen (2015) identified 30 government-led critical success factors and their importance (CSFs) from both micro and macro levels in public-private partnership (PPP) infrastructure development. The research has evaluated the government performance within the Indonesian context. Dang and Le-Hoai (2016) used the critical success factors (CSFs) to identify the correlation between critical success factors (CSFs) and Design-Build projects' performance measured by key performance indicators (KPIs). Nilashi et al. (2015) highlighted the importance levels of interdependency among the CSFs and most influential factors in successfully completing construction projects have been used to develop a new integrated model, multi-criteria construction projects CSF model but without considering the organizational level.

\section{Analytic Hierarchy Process (AHP) Framework}

Saaty, 2008 developed the Analytic Hierarchy Process (AHP) as a general theory of quantifying the effect of qualitative factors. It is a noncomplicated technique that attempts to simulate the human decision-making process and a multicriteria decision-making method (Goepel, 2013). AHP has been developed to assist in solving complicated decision-making process through aggregating thoughts, experiences, knowledge, and judgment into a hierarchical framework. AHP mainly works through a sequence of pair-wise comparisons between the factors that influence the decision making process (Al-Barqawi and Zayed, 2008). It deals with both qualitative and quantitative criteria that affect the decision making process. Ersoz (1995) highlighted the importance of AHP in its power to quantifying the intangible decision criteria. 
AHP theory has been widely utilized for planning decisions, resource allocation, conflict resolution, and assessment problems (Al-Barqawi et al., 2008). AHP has been implemented in many research works in different fields. Al-Harbi (2001) applied AHP as a decision-making tool for project managers. Korpela and Tuominen (1996) utilized AHP in the selection process of contractors for specific projects, based on qualification criteria considering both quantitative and qualitative aspects in the selection process.

Three main principles are the basics of solving a problem (Saaty, 1990) as follows: 1) developing the hierarchies; 2) setting the priorities; 3 ) ensuring logical consistency with in the factors. For developing an AHP model, six steps are required (Al Khalil, 2002, Saaty, 1990,2008):

1. Identify the factors that contribute to solving the problem, and categorize them hierarchically;

2. Assign the relative weights of the factors and sub-factors in each category using pairwise comparisons between each pair in the same hierarchy. The weight of each factors represents the relative importance of the factor among its peers. A comparison matrix is then developed as follows:

Factors comparisons

$$
=\left[\begin{array}{ccc}
1 & x & y \\
1 / x & 1 & z \\
1 / y & 1 / z & 1
\end{array}\right]
$$

Where $\mathrm{x}, \mathrm{y}$, and $\mathrm{z}$ are numbers (integers or non-integers)

3. If the developed matrix is consistent. Then the weight vector for all the qualitative factors will calculated by elevating the matrix to different powers and normalizing the matrix (i.e. converting the summation of each column to be one) at these powers. The produced normalized column is the eigenvector. This process is repeated until the eigenvector solution is not changing from the previous iteration (i.e. up to four decimal places 0.0001).

4. If the matrix is not consistent, it has to be returned to the expert to adjust the response and to be consistent in the values. Once it is consistent, step three is repeated.

5. Consistency Index or eigenvalue (CI) is the calculated value used to check the matrix consistency as follows:

$$
C I=\left(\lambda_{\max }-d\right) /(d-1)
$$

Where $\lambda$ max is the maximum eigenvector and $d$ is the matrix dimensions

6. Consistency ratio (CR) is then calculated as follows:

$$
C R=C I / R I
$$

Where CI is the consistency index, and RI is the random index which is the average C.I. of sets of judgments (from a 1 to 9 scale) for randomly generated reciprocal matrices, to indicate whether the estimates are closer to being consistent or to being randomly assigned. According to Saaty (1990), if the CR is more than $10 \%$, then the results are inconsistent. Thus, the values should be changed until $\mathrm{CR}$ is verified.

\section{Methodology}

To achieve the objectives of this research, several steps have been accomplished as shown in the schematic diagram Figure 1 shows a graphical representation of the methodology. It starts with reviewing the previous literature and the existing models in order to identify the critical success factors in construction organizations. Experts have been contacted to determine the weights and the impact of the factors that contribute mostly to the organization performance. This research has assumed the professional with more than 25 years of experience is an expert. Because this research methodology is a qualitative expert based research, the Neural Network Analysis technique and 
Figure 1: Research Methodology.

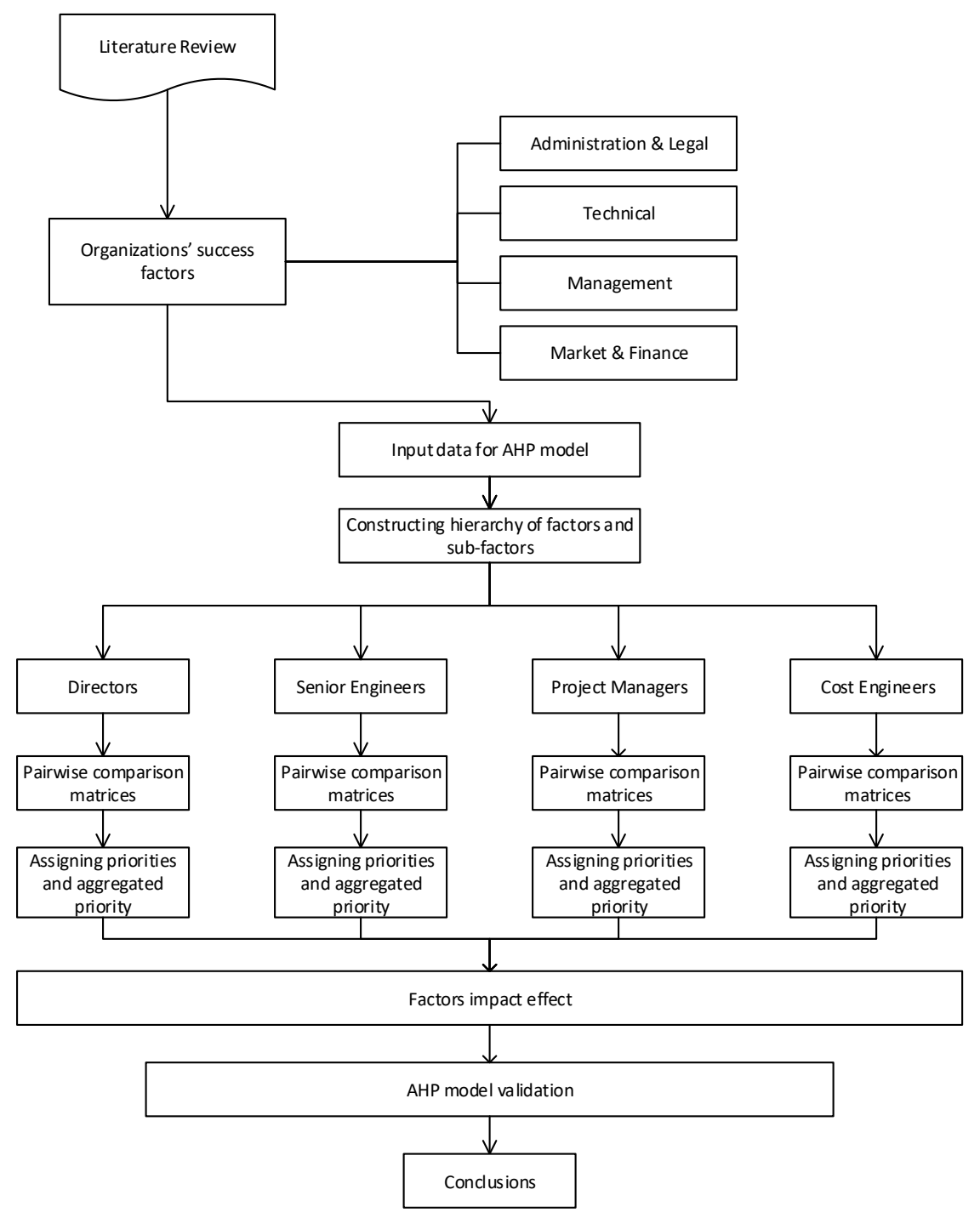

Regression Analysis technique were excluded. However, the correlation/dependency between variables were examined. In terms of dependency, a correlation test was conducted in the Minitab software. No dependency between the variables was found because the $\mathrm{p}$ variables were less than 0.05. Therefore, the ANP was excluded based on the results of the dependency test. The AHP will be applied using the data collected form the experts and the pairwise comparisons. Then a performance scale will be developed to assess the organizational performance based on the perspective of the functional units and how they perceive the CSFs.

The AHP has been selected because it is knowledge-based oriented technique that requires experts' opinions to accommodate the success in assessing organization performance. The developed models have been validated using actual data. 


\section{Data Collection}

Based upon the literature and expert opinions, the critical success factors (CSFs) were identified. Four main factors were identified as the main categories to be included in the model (i.e. administration \& legal, technical, management, and market $\&$ finance). Those four main factors represent the main aspects of practice in any successful organization. Eighteen sub-factors are included in the model. The attributes effect of the factors is collected through utilizing likert-scale questionnaire to the experts. The idea is to identify the different perspectives of each functional unit within the organization.

Data collection involved two main stages; 1 ) pairwise comparisons of the main factors and subfactors; 2) identifying the impact of each factor on the performance of the organization. A questionnaire was administered to different functional units in construction organizations to reflect their experience and the company performance form their perspective. 150 questionnaires were sent to basic functional units in construction organizations. The returned survey from the different respondent groups are shown in Table 1.

\section{AHP Model Development}

The AHP model is developed to assess the performance of the construction organizations from the perspective of four different functional units teams (i.e. directors, senior engineers, project managers, cost engineers), based on the four main

Table 1: Survey Return Data.

\begin{tabular}{ccccc}
\hline & Directors & \multicolumn{2}{c}{ Functional Units' Teams } & Senior \\
Engineers & $\begin{array}{c}\text { Project } \\
\text { Managers }\end{array}$ & $\begin{array}{c}\text { Cost } \\
\text { Engineers }\end{array}$ \\
\hline $\begin{array}{c}\text { Number of } \\
\text { Responses }\end{array}$ & 12 & 20 & 21 & 10 \\
\hline $\begin{array}{c}\text { Response } \\
\text { rate } \\
\text { proportion } \\
(\%)\end{array}$ & $19 \%$ & $32 \%$ & $33 \%$ & $16 \%$ \\
\hline
\end{tabular}

Total 63 success categorize that forms the critical success factors.

\section{Factors Weights}

The following steps are the guide for the model development (Al-Barqawi and Zayed, 2006).

\section{Step 1: Setting up the factors hierarchy}

The factor that affect the organizations performance are divided into three main levels as shown in Figure 2. Level one represents the main objective of the factors (i.e. assessment of organizations performance). Level two represents the four main factors (i.e. administration \& legal, technical, management, and market \& finance). While level three represents the model sub-factors or the 18 critical success factors (e.g. organizational structure, employee culture environment, business experience). This step is identical in the four functional units' models.

\section{Step 2: Assigning priorities and establish priority vector (eigenvector)}

In this step, the functional units' individuals and industry experts provide pairwise comparison matrices for the main factors and sub-factors. Using pairwise comparisons allows the individuals to express the relative importance of one factor over another. AHP analysis is applied to determine the factors weight $\left(W_{i}\right)$ and sub-factors weight $\left(S W_{i j}\right)$ of each factor based on the individuals' input. For example, in the directors' model, the analysis from one of the respondents are as shown

in Table 2. This step is repeated for all the respondents form all the functional units.

The analysis shows that the weight $\left(W_{i}\right)$ of administrative \& legal factors has the highest priority and impact on the organization's performance from the perspective of a director $(28.3 \%)$. On the other hand, management factor has the lowest effect of $(21.7 \%)$. In addition, clear vision, mission \& goals, political conditions, and 
Figure 2: The Developed Model Hierarchy

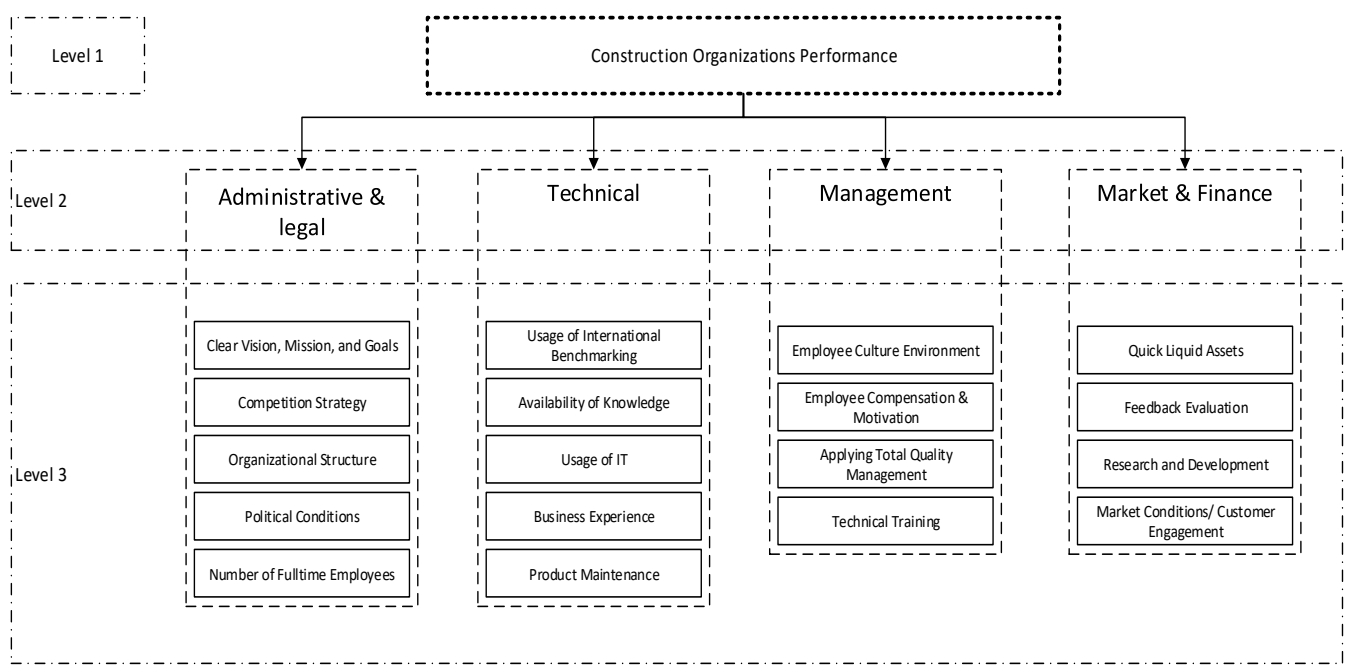

no of full time employees' sub-factors has the highest weights $\left(S W_{i j}\right)$ in the administrative \& legal factors $(23.5 \%)$; availability of knowledge and business experience has the highest weights in the technical factor (30\%). Employee compensation and motivation is the highest in the management factor (40\%); and finally, the quick liquid assets and market Conditions are the highest in the market $\&$ finance factor $(33 \%)$.

Table 2: Analysis from One Respondent (Director)

\begin{tabular}{|c|c|c|c|c|c|}
\hline $\begin{array}{c}\text { Main } \\
\text { Performance } \\
\text { factors }\end{array}$ & $W_{i}$ & sub-factor & $S W_{i j}$ & $C I$ & $C R \%$ \\
\hline \multirow{5}{*}{$\begin{array}{l}\text { Administrative } \\
\quad \& \text { Legal }\end{array}$} & \multirow{5}{*}{0.283} & Clear Vision, Mission \& Goals X1 & 0.2353 & \multirow{5}{*}{0.003} & \multirow{5}{*}{$0.40 \%$} \\
\hline & & Competition Strategy X2 & 0.1765 & & \\
\hline & & Organizational Structure X3 & 0.1176 & & \\
\hline & & Political Conditions X4 & 0.2353 & & \\
\hline & & No of Full Time Employees X5 & 0.2353 & & \\
\hline \multirow{5}{*}{ Technical } & \multirow{5}{*}{0.278} & Usage of International Aspects X6 & 0.0769 & \multirow{5}{*}{0.04} & \multirow{5}{*}{$0.76 \%$} \\
\hline & & Availability of knowledge X7 & 0.3077 & & \\
\hline & & Usage of IT X8 & 0.0769 & & \\
\hline & & Business Experience (no. of years) X9 & 0.3077 & & \\
\hline & & Product Maintenance X10 & 0.2308 & & \\
\hline \multirow{4}{*}{ Management } & \multirow{4}{*}{0.217} & Employee Culture Environment X11 & 0.3000 & \multirow{4}{*}{0.00} & \multirow{4}{*}{0.00} \\
\hline & & Employee Compensation and Motivation X12 & 0.4000 & & \\
\hline & & Applying TQM X13 & 0.1000 & & \\
\hline & & Training X14 & 0.2000 & & \\
\hline \multirow{4}{*}{$\begin{array}{l}\text { Market \& } \\
\text { Finance }\end{array}$} & \multirow{4}{*}{0.222} & Quick Liquid Assets X15 & 0.3333 & \multirow{4}{*}{0.006} & \multirow{4}{*}{$1.74 \%$} \\
\hline & & Feedback Evaluation X16 & 0.1667 & & \\
\hline & & Research and Development X17 & 0.1667 & & \\
\hline & & Market Conditions/Customer Engagement X18 & 0.3333 & & \\
\hline
\end{tabular}

The Engineering Project Organization Journal (C)2017 Engineering Project Organization Society www.epossociety.org 


\section{Step 3: Responses Consistency Analysis}

Consistency of the pairwise comparison matrices are tested using Equations (1) and (2) above. Table 2 shows the values of $C I$ and $C R$ for the sub-factors' matrices of one of the responses on the directors' model. The CR values all are less than $10 \%$ which is the acceptable range according to (Saaty, 2008). All the matrices that were received from experts are consistent. This step is repeated for all the matrices in all the four assessment models.

\section{Step 4: Aggregated priority weights}

Priority weights aggregation comes after the consistency analysis. Where the aggregated weight of each sub-factor is calculated by multiplying the sub-factor weight $\left(S W_{i j}\right)$ by the corresponding main factor weight $\left(W_{i}\right)$ of the same category. Accordingly, priority can be established based on the overall weight using Equation (3) as follows:
Overall subfactors aggregated weight $A S W_{i j}=$

$$
W_{i} \times S W_{i j}
$$

Where $\left(A S W_{i j}\right)$ is the aggregated weight of the sub-factor, $(W i)$ is the weight of the main factor, and $\left(S W_{i j}\right)$ is the weight of sub-factor $j$ in the $i^{\text {th }}$ factor.

Tables 3, 4, 5, and 6 shows the results of the aggregation process based on the average values for the collected matrices of the directors, senior engineers, project managers, and cost engineers' functional units' models respectively.

Table 3: Average Aggregated Weights for the Directors Model

\begin{tabular}{|c|c|c|c|c|c|c|}
\hline $\begin{array}{l}\text { Main } \\
\text { Performance } \\
\text { factors }\end{array}$ & $W_{i}$ & sub-factor & $S W_{i j}$ & $\begin{array}{c}A S W_{i j} \\
\%\end{array}$ & $\begin{array}{l}\text { Sub- } \\
\text { factors } \\
\text { ranking }\end{array}$ & $\begin{array}{l}\text { Overall } \\
\text { ranking }\end{array}$ \\
\hline \multirow{5}{*}{$\begin{array}{l}\text { Administrative } \\
\text { \& Legal }\end{array}$} & \multirow{5}{*}{0.283} & Clear Vision, Mission \& Goals X1 & 0.222 & $6.28 \%$ & 1 & 3 \\
\hline & & Competition Strategy X2 & 0.217 & $6.14 \%$ & 2 & 4 \\
\hline & & Organizational Structure X3 & 0.201 & $5.68 \%$ & 3 & 8 \\
\hline & & Political Conditions X4 & 0.183 & $5.16 \%$ & 4 & 15 \\
\hline & & No of Full Time Employees X5 & 0.177 & $5.01 \%$ & 5 & 17 \\
\hline \multirow{5}{*}{ Technical } & \multirow{5}{*}{0.278} & Usage of International Aspects X6 & 0.154 & $4.29 \%$ & 5 & 18 \\
\hline & & Availability of knowledge $\mathrm{X} 7$ & 0.226 & $6.30 \%$ & 2 & 2 \\
\hline & & Usage of IT X8 & 0.207 & $5.81 \%$ & 3 & 6 \\
\hline & & Business Experience (no. of years) X9 & 0.231 & $6.43 \%$ & 1 & 1 \\
\hline & & Product Maintenance X10 & 0.180 & $5.02 \%$ & 4 & 16 \\
\hline \multirow{4}{*}{ Management } & \multirow{4}{*}{0.217} & Employee Culture Environment X11 & 0.249 & $5.42 \%$ & 2 & 10 \\
\hline & & Employee Compensation and Motivation X12 & 0.264 & $5.74 \%$ & 1 & 7 \\
\hline & & Applying TQM X13 & 0.242 & $5.25 \%$ & 4 & 14 \\
\hline & & Training X14 & 0.245 & $5.32 \%$ & 3 & 12 \\
\hline \multirow{4}{*}{$\begin{array}{l}\text { Market \& } \\
\text { Finance }\end{array}$} & \multirow{4}{*}{0.222} & Quick Liquid Assets X15 & 0.250 & $5.55 \%$ & 2 & 9 \\
\hline & & Feedback Evaluation X16 & 0.243 & $5.39 \%$ & 3 & 11 \\
\hline & & Research and Development X17 & 0.238 & $5.26 \%$ & 4 & 13 \\
\hline & & Market Conditions/Customer Engagement X18 & 0.269 & $5.96 \%$ & 1 & 5 \\
\hline
\end{tabular}


Table 4: Average Aggregated Weights for the Senior Engineers Model

\begin{tabular}{|c|c|c|c|c|c|c|}
\hline $\begin{array}{l}\text { Main } \\
\text { Performance } \\
\text { factors }\end{array}$ & $W_{i}$ & sub-factor & $S W_{i j}$ & $\begin{array}{c}A S W_{i j} \\
\%\end{array}$ & $\begin{array}{l}\text { Sub- } \\
\text { factors } \\
\text { ranking }\end{array}$ & $\begin{array}{l}\text { Overall } \\
\text { ranking }\end{array}$ \\
\hline \multirow{5}{*}{$\begin{array}{l}\text { Administrative } \\
\quad \& \text { Legal }\end{array}$} & \multirow{5}{*}{0.219} & Clear Vision, Mission \& Goals X1 & 0.226 & $4.96 \%$ & 1 & 12 \\
\hline & & Competition Strategy X2 & 0.204 & $4.47 \%$ & 3 & 15 \\
\hline & & Organizational Structure X3 & 0.210 & $4.61 \%$ & 2 & 14 \\
\hline & & Political Conditions X4 & 0.187 & $4.10 \%$ & 4 & 17 \\
\hline & & No of Full Time Employees X5 & 0.174 & $3.81 \%$ & 5 & 18 \\
\hline \multirow{5}{*}{ Technical } & \multirow{5}{*}{0.271} & Usage of International Aspects X6 & 0.161 & $4.36 \%$ & 5 & 16 \\
\hline & & Availability of knowledge X7 & 0.208 & $5.63 \%$ & 3 & 7 \\
\hline & & Usage of IT X8 & 0.213 & $5.76 \%$ & 2 & 5 \\
\hline & & Business Experience (no. of years) X9 & 0.223 & $6.03 \%$ & 1 & 3 \\
\hline & & Product Maintenance X10 & 0.196 & $5.29 \%$ & 4 & 9 \\
\hline \multirow{4}{*}{ Management } & \multirow{4}{*}{0.224} & Employee Culture Environment X11 & 0.226 & $5.06 \%$ & 4 & 11 \\
\hline & & Employee Compensation and Motivation X12 & 0.268 & $6.01 \%$ & 2 & 4 \\
\hline & & Applying TQM X13 & 0.232 & $5.19 \%$ & 3 & 10 \\
\hline & & Training X14 & 0.275 & $6.16 \%$ & 1 & 1 \\
\hline \multirow{4}{*}{$\begin{array}{l}\text { Market \& } \\
\text { Finance }\end{array}$} & \multirow{4}{*}{0.220} & Quick Liquid Assets X15 & 0.260 & $5.71 \%$ & 2 & 6 \\
\hline & & Feedback Evaluation X16 & 0.245 & $5.38 \%$ & 3 & 8 \\
\hline & & Research and Development X17 & 0.214 & $4.71 \%$ & 4 & 13 \\
\hline & & Market Conditions/Customer Engagement X18 & 0.280 & $6.14 \%$ & 1 & 2 \\
\hline
\end{tabular}

Table 5: Average Aggregated Weights for the Project Managers Model

\begin{tabular}{|c|c|c|c|c|c|c|}
\hline $\begin{array}{l}\text { Main } \\
\text { Performance } \\
\text { factors }\end{array}$ & $W_{i}$ & sub-factor & $S W_{i j}$ & $\begin{array}{c}A S W_{i j} \\
\%\end{array}$ & $\begin{array}{c}\text { Sub- } \\
\text { factors } \\
\text { ranking }\end{array}$ & $\begin{array}{l}\text { Overall } \\
\text { ranking }\end{array}$ \\
\hline \multirow{5}{*}{$\begin{array}{l}\text { Administrative } \\
\text { \& Legal }\end{array}$} & \multirow{5}{*}{0.287} & Clear Vision, Mission \& Goals X1 & 0.227 & $6.48 \%$ & 1 & 1 \\
\hline & & Competition Strategy X2 & 0.214 & $6.11 \%$ & 2 & 3 \\
\hline & & Organizational Structure X3 & 0.208 & $5.95 \%$ & 3 & 6 \\
\hline & & Political Conditions X4 & 0.178 & $5.08 \%$ & 4 & 14 \\
\hline & & No of Full Time Employees X5 & 0.173 & $4.94 \%$ & 5 & 17 \\
\hline \multirow{5}{*}{ Technical } & \multirow{5}{*}{0.276} & Usage of International Aspects X6 & 0.158 & $4.36 \%$ & 5 & 18 \\
\hline & & Availability of knowledge X7 & 0.220 & $6.06 \%$ & 2 & 4 \\
\hline & & Usage of IT X8 & 0.212 & $5.86 \%$ & 3 & 7 \\
\hline & & Business Experience (no. of years) X9 & 0.223 & $6.17 \%$ & 1 & 2 \\
\hline & & Product Maintenance X10 & 0.187 & $5.16 \%$ & 4 & 13 \\
\hline \multirow{4}{*}{ Management } & \multirow{4}{*}{0.219} & Employee Culture Environment X11 & 0.242 & $5.29 \%$ & 3 & 12 \\
\hline & & Employee Compensation and Motivation X12 & 0.263 & $5.75 \%$ & 2 & 9 \\
\hline & & Applying TQM X13 & 0.231 & $5.06 \%$ & 4 & 15 \\
\hline & & Training X14 & 0.264 & $5.78 \%$ & 1 & 8 \\
\hline \multirow{4}{*}{$\begin{array}{l}\text { Market \& } \\
\text { Finance }\end{array}$} & \multirow{4}{*}{0.220} & Quick Liquid Assets X15 & 0.248 & $5.43 \%$ & 3 & 11 \\
\hline & & Feedback Evaluation X16 & 0.250 & $5.49 \%$ & 2 & 10 \\
\hline & & Research and Development X17 & 0.227 & $4.98 \%$ & 4 & 16 \\
\hline & & Market Conditions/Customer Engagement X18 & 0.275 & $6.04 \%$ & 1 & 5 \\
\hline
\end{tabular}


The Engineering Project Organization Journal (December 2018) Volume 8

Table 6: Average Aggregated Weights for the Cost Engineers Model

\begin{tabular}{|c|c|c|c|c|c|c|}
\hline $\begin{array}{l}\text { Main } \\
\text { Performance } \\
\text { factors }\end{array}$ & $W_{i}$ & sub-factor & $S W_{i j}$ & $\begin{array}{c}A S W_{i j} \\
\%\end{array}$ & $\begin{array}{l}\text { Sub- } \\
\text { factors } \\
\text { ranking }\end{array}$ & $\begin{array}{l}\text { Overall } \\
\text { ranking }\end{array}$ \\
\hline \multirow{5}{*}{$\begin{array}{l}\text { Administrative } \\
\text { \& Legal }\end{array}$} & \multirow{5}{*}{0.288} & Clear Vision, Mission \& Goals X1 & 0.227 & $6.54 \%$ & 1 & 1 \\
\hline & & Competition Strategy X2 & 0.209 & $6.02 \%$ & 2 & 4 \\
\hline & & Organizational Structure X3 & 0.203 & $5.86 \%$ & 3 & 6 \\
\hline & & Political Conditions X4 & 0.187 & $5.39 \%$ & 4 & 11 \\
\hline & & No of Full Time Employees X5 & 0.174 & $5.02 \%$ & 5 & 15 \\
\hline \multirow{5}{*}{ Technical } & \multirow{5}{*}{0.279} & Usage of International Aspects X6 & 0.157 & $4.38 \%$ & 5 & 18 \\
\hline & & Availability of knowledge X7 & 0.217 & $6.06 \%$ & 2 & 3 \\
\hline & & Usage of IT X8 & 0.204 & $5.71 \%$ & 3 & 8 \\
\hline & & Business Experience (no. of years) X9 & 0.230 & $6.43 \%$ & 1 & 2 \\
\hline & & Product Maintenance X10 & 0.192 & $5.38 \%$ & 4 & 12 \\
\hline \multirow{4}{*}{ Management } & \multirow{4}{*}{0.216} & Employee Culture Environment X11 & 0.247 & $5.35 \%$ & 3 & 13 \\
\hline & & Employee Compensation and Motivation X12 & 0.267 & $5.76 \%$ & 1 & 7 \\
\hline & & Applying TQM X13 & 0.230 & $4.97 \%$ & 4 & 16 \\
\hline & & Training X14 & 0.256 & $5.54 \%$ & 2 & 10 \\
\hline \multirow{4}{*}{$\begin{array}{l}\text { Market \& } \\
\text { Finance }\end{array}$} & \multirow{4}{*}{0.216} & Quick Liquid Assets X15 & 0.258 & $5.58 \%$ & 2 & 9 \\
\hline & & Feedback Evaluation X16 & 0.242 & $5.23 \%$ & 3 & 14 \\
\hline & & Research and Development X17 & 0.224 & $4.85 \%$ & 4 & 17 \\
\hline & & Market Conditions/Customer Engagement X18 & 0.276 & $5.95 \%$ & 1 & 5 \\
\hline
\end{tabular}

Figure 3: Ranking of the CSFs among the Functional Units

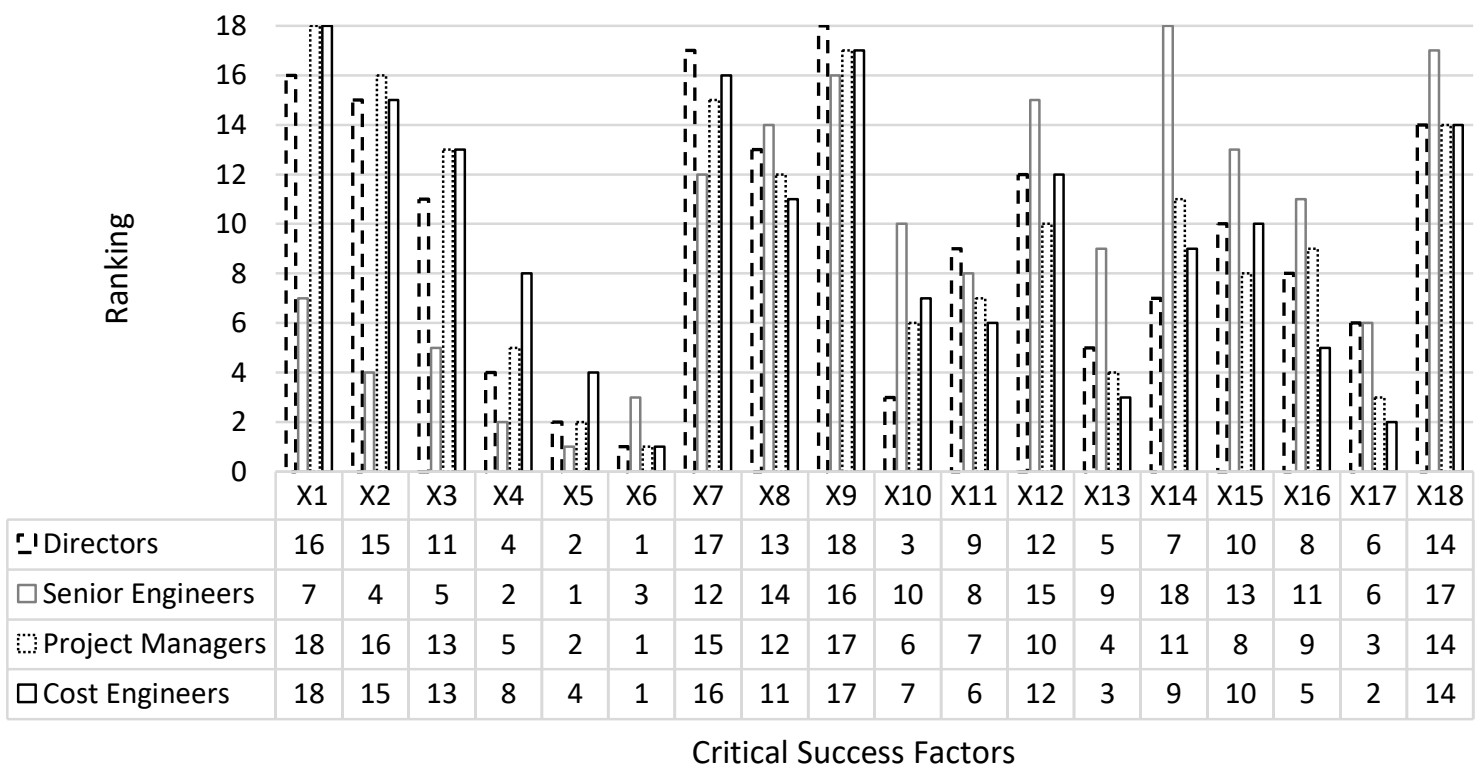

The Engineering Project Organization Journal (C)2017 Engineering Project Organization Society www.epossociety.org 
From the tables, it is noticed that the administrative \& legal factor is the highest factor contributes to the construction organizations' performance in the directors, project managers, and senior engineers model with $28 \%$. While the technical factors were found to be the highest weight in the senior engineers' model with $27 \%$.
This shows the importance of the technical factor to the engineers. Figure 3 shows the relative importance of the sub-factors in each model. Where 18 represents the highest ranking and the most important factor to the functional unit, while 1 represents the lowest ranking and the least important factor to the functional units.

Table 7: Average Attributes Impact of the Sub-factors

\begin{tabular}{|c|c|c|c|}
\hline Factors & Sub-Factors & Attributes & $F A I_{i j}$ \\
\hline \multirow{21}{*}{ 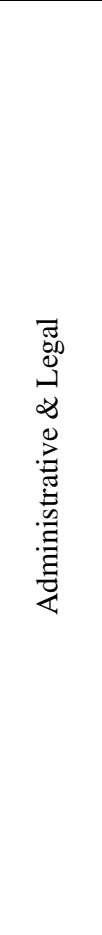 } & \multirow{5}{*}{ Clear vision, mission \& goals X1 } & Very Good & 10 \\
\hline & & Good & 8 \\
\hline & & Moderate & 6 \\
\hline & & Bad & 4 \\
\hline & & Very Bad & 2 \\
\hline & \multirow{2}{*}{ Competition strategy X2 } & Very Good & 10 \\
\hline & & Good & 8 \\
\hline & \multirow{7}{*}{ Organizational structure X3 } & Moderate & 6 \\
\hline & & $\mathrm{Bad}$ & 4 \\
\hline & & Very Bad & 2 \\
\hline & & Very Good & 10 \\
\hline & & Good & 8 \\
\hline & & Moderate & 6 \\
\hline & & Bad & 4 \\
\hline & \multirow{4}{*}{ Political conditions X4 } & Very Bad & 2 \\
\hline & & Good & 8 \\
\hline & & Moderate & 6 \\
\hline & & $\mathrm{Bad}$ & 2 \\
\hline & \multirow[t]{3}{*}{ No of full time employees X5 } & High & 9 \\
\hline & & Moderate & 7 \\
\hline & & Low & 5 \\
\hline \multirow{13}{*}{ 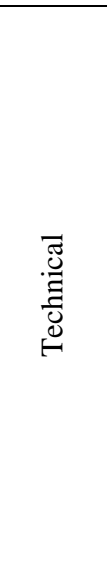 } & \multirow[t]{3}{*}{ Usage of international aspects X6 } & Good & 8 \\
\hline & & Moderate & 6 \\
\hline & & Bad & 4 \\
\hline & \multirow[t]{2}{*}{ Availability of knowledge X7 } & High & 10 \\
\hline & & Moderate & 6 \\
\hline & \multirow{3}{*}{ Usage of IT X8 } & Low & 2 \\
\hline & & High & 10 \\
\hline & & Low & 6 \\
\hline & \multirow[t]{3}{*}{ Business experience (no. of years) X9 } & High & 9 \\
\hline & & Moderate & 7 \\
\hline & & Low & 5 \\
\hline & \multirow[t]{2}{*}{ Product maintenance X10 } & Good & 7 \\
\hline & & Bad & 5 \\
\hline
\end{tabular}


Table 7: Average Attributes Impact of the Sub-factors (continued)

\begin{tabular}{|c|c|c|c|c|}
\hline Factors & Sub-Factors & & Attributes & $F A I_{i j}$ \\
\hline \multirow{11}{*}{ 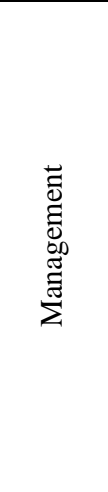 } & Employee culture environment & $\mathrm{X} 11$ & Good & 8 \\
\hline & & & Moderate & 6 \\
\hline & & & $\mathrm{Bad}$ & 4 \\
\hline & Employee compensation and motivation & $\mathrm{X} 12$ & High & 10 \\
\hline & & & Moderate & 6 \\
\hline & & & Low & 2 \\
\hline & Applying TQM & $\mathrm{X} 13$ & High & 8 \\
\hline & & & Low & 6 \\
\hline & Training & X14 & High & 10 \\
\hline & & & Moderate & 6 \\
\hline & & & Low & 4 \\
\hline \multirow{11}{*}{ 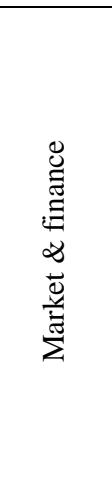 } & Quick liquid assets & $\mathrm{X} 15$ & Good & 10 \\
\hline & & & Moderate & 8 \\
\hline & & & Bad & 4 \\
\hline & Feedback evaluation & X16 & High & 10 \\
\hline & & & Moderate & 8 \\
\hline & & & Low & 6 \\
\hline & Research and development & $\mathrm{X} 17$ & Good & 8 \\
\hline & & & $\mathrm{Bad}$ & 6 \\
\hline & Market conditions/customer engagement & $\mathrm{X} 18$ & High & 8 \\
\hline & & & Moderate & 6 \\
\hline & & & Low & 4 \\
\hline
\end{tabular}

\section{Model Implementation}

\section{Step 5: Calculating factors attributes impact $\left(\boldsymbol{F A} \boldsymbol{I}_{i j}\right)$}

The aggregated weights represent a generic global weight for the factors and the corresponding sub-factors. However, each factor consists of various attributes that can impact the organizations' performance differently. For instance, as shown in Table 7 , the sub-factor "political conditions" has three different attributes that impact the model differently (good, moderate, bad). Thus, the impact of those attributes on the performance is considered through the attributes effect. The industry experts were asked to assign factors' attributes impact $\left(F A I_{i j}\right)$ for each sub-factor using a " 0 " to " 10 " scale, where " 0 " represents the least impact and " 10 " represents the highest impact. Table 7 shows the average attributes impact for all the sub-factors. The $F A I_{i j}$ is the same for all the four models.

\section{Step 6: Organizations' performance assessment model}

The last step of the AHP modeling is to develop the organizations performance assessment model (OPAM). The assessment is based on a scale of ( 0 to 10$)$ as shown in Figure 4. 
Figure 4. Proposed Performance Assessment Scale

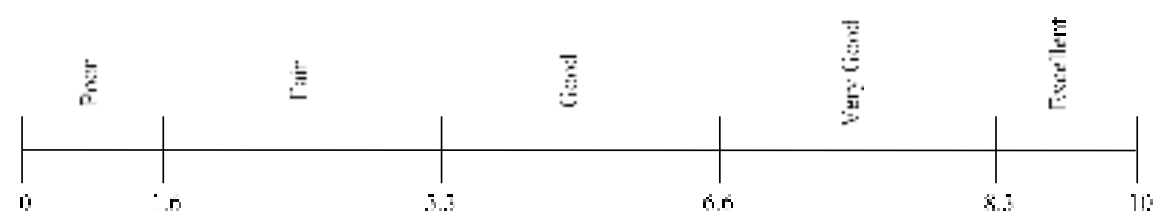

The output of the model is compared to the proposed scale in Figure 4. Using Equations 4 and 5 , the AHP model is mathematically developed by combining the different priority matrices with the

$$
O P A M=\sum_{i=1}^{n} \sum_{j=1}^{m}\left(W_{i}\right)\left(S W_{i j}\right)\left(F A I_{i j}\right)
$$
factors attributes impact. The results of the models will help the organizations to assess their performance based on the different functional units to identify the weakness and improve the performance. A sample of construction organizations' data from one of the directors is shown in Table 8.

\section{Organizations performance}

$$
\begin{aligned}
& \text { assessment model (OPAM) } \\
& =\sum_{i=1}^{n} \sum_{j=1}^{m}\left(A S W_{i j}\right)\left(F A I_{i j}\right)
\end{aligned}
$$

Where $n$ is the number of factors $i, m$ is the number of sub-factors $j$ within the main factor $i$

Table 8: A Sample of Directors Perspective Data

\begin{tabular}{cccccc}
\hline Factors & \multicolumn{5}{c}{ Sub-factors } \\
\hline Administration \& legal & $\mathrm{X} 1$ & $\mathrm{X} 2$ & $\mathrm{X} 3$ & $\mathrm{X} 4$ & $\mathrm{X} 5$ \\
& 8 & 8 & 8 & 10 & 8 \\
\hline Technical & $\mathrm{X} 6$ & $\mathrm{X} 7$ & $\mathrm{X} 8$ & $\mathrm{X} 9$ & $\mathrm{X} 10$ \\
& 4 & 8 & 8 & $\mathrm{X}$ & 4 \\
\hline Management & $\mathrm{X} 11$ & $\mathrm{X} 12$ & $\mathrm{X} 13$ & $\mathrm{X} 14$ \\
& 6 & 6 & 8 & $\mathrm{X} 18$ \\
Market \& Finance & $\mathrm{X} 15$ & $\mathrm{X} 16$ & 6 & 4 \\
\hline Organization & 6 & 6 & \multicolumn{3}{c}{ Very good } \\
Performance & \multicolumn{5}{c}{} \\
\hline
\end{tabular}




\section{AHP Model Validation}

A $20 \%$ of the responses from each functional unit is selected randomly to be utilized to test the ability of the models to assess the organizational performance using the Average Invalidity Percent (AIP) and the Average Validity Percent (AVP) as shown in Equation 6 and 7.

$$
\begin{aligned}
& \text { Average validity percent (AVP \%) } \\
& =[|V 1-V 2| /((V 1+V 2) / 2)] \\
& \times 100
\end{aligned}
$$

Average invalidity percent (AIP \%) ....

$$
=1-\mathrm{AVP}
$$

$V 1$ is the outcome value, and $V 2$ is the actual value. Table 9 shows a sample of the validation dataset being utilized, as well as the AVP and AIP for the models.

The table shows satisfactory results for the accuracy values of the directors, senior engineers, project managers, and cost engineers models are $85 \%, 80 \%, 90 \%$, and $85 \%$ respectively. The results show that the project managers' model is closer to the actual data than the other models which shows the effect of number of data sets on the validation results as the Manager data percent is the highest "33\%". Figure 5 shows graphically the difference between the actual and predicted values of the overall organization performance for the four developed models which shows a close pattern behavior.

Table 9: Models Validation Samples

\begin{tabular}{cccccc}
\hline Model & $\begin{array}{c}\text { Validation } \\
\text { cases }\end{array}$ & $\begin{array}{c}\text { Actual } \\
\text { performance }\end{array}$ & $\begin{array}{c}\text { Modeled } \\
\text { performance }\end{array}$ & AVP & $\sum$ AVP and $\sum$ AIP \\
\hline \multirow{2}{*}{ Directors } & 26 & 85 (excellent) & 70 (very good) & $20 \%$ & \\
& 25 & 60 (good) & 52 (good) & $14 \%$ & $\sum$ AVP $=15 \%$ \\
& 24 & 85 (excellent) & 80 (very good) & $17 \%$ & \\
\hline \multirow{2}{*}{ Senior } & 25 & 80 (very good) & 75 (very good) & $6 \%$ & \\
Engineers & 24 & 75 (very good) & 50 (good) & $40 \%$ & $\sum$ AVP $=20 \%$ \\
& 23 & 94 (excellent) & 76 (very good) & $24 \%$ & \\
\hline \multirow{2}{*}{ Project } & 52 & 80 (very good) & 72 (very good) & $9 \%$ & \\
Managers & 51 & 75 (very good) & 72 (very good) & $3 \%$ & $\sum$ AVP $=10 \%$ \\
& 50 & 80 (very good) & 70 (very good) & $13 \%$ & \\
\hline \multirow{2}{*}{ Cost } & 51 & 60 (good) & 52 (good) & $13 \%$ & \\
Engineers & 50 & 95 (excellent) & 80 (very good) & $17 \%$ & $\sum$ AVP $=15 \%$ \\
& 49 & 95 (excellent) & 83 (excellent) & $12 \%$ & \\
\hline
\end{tabular}


Figure 5: Actual performance Vs. Modeled performance

Directors

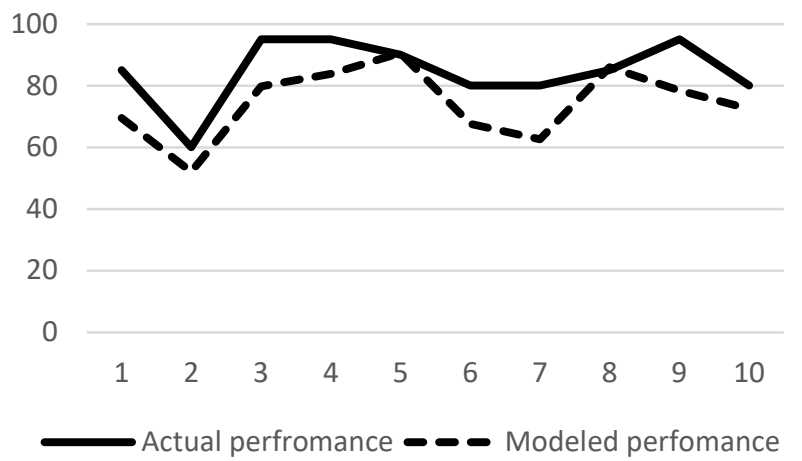

Actual Vs. Predicted values for the Directors Model

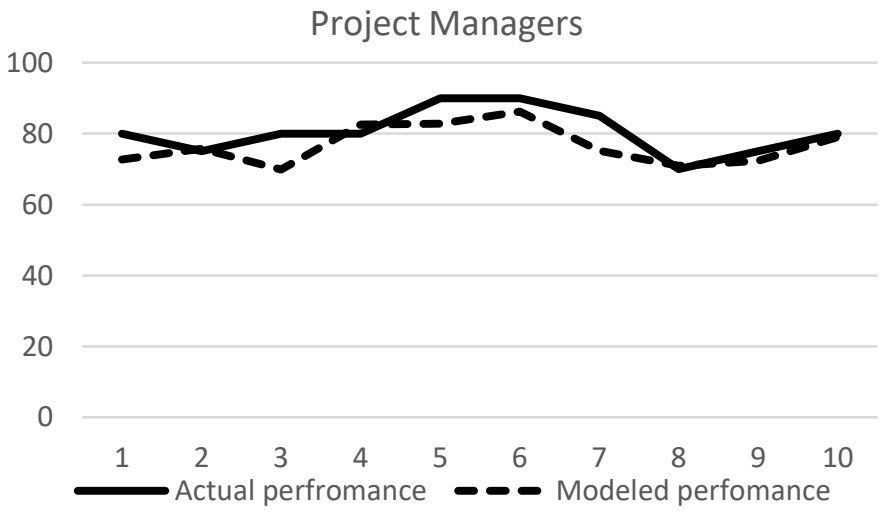

Actual Vs. Predicted values for the Project Management Model

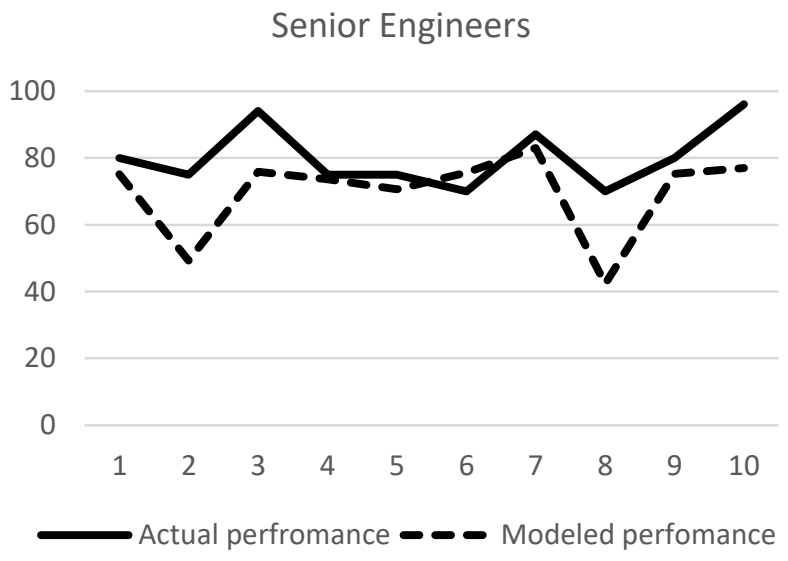

Actual Vs. Predicted values for the Senior Engineers

Model

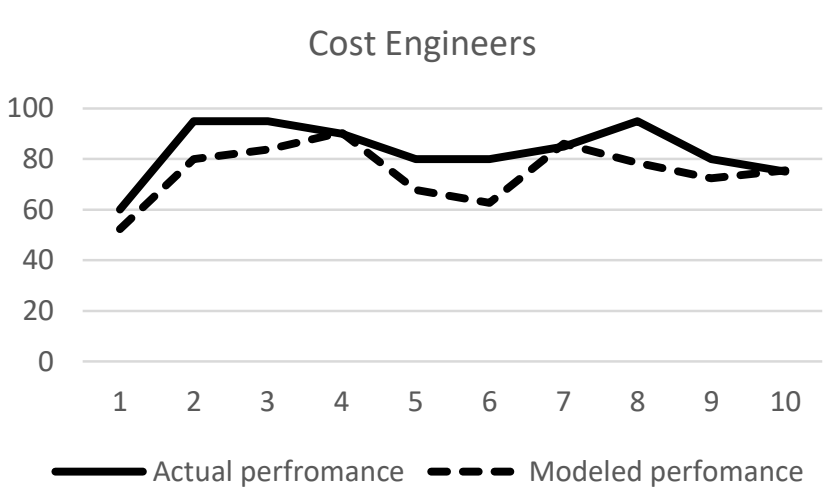

Actual Vs. Predicted values for the Cost Engineer

Model

\section{Conclusion and Discussion}

Modeling the performance of construction organizations from a financial prospective has been extensively researched; however, modeling the performance considering non-financial aspects has not receive sufficient attention from researchers. The results and practitioners and experts' opinions have supported the importance of approaching the performance from different perspectives of different project roles. The study focused on how critical success factors can be perceived differently from one functional unit to another in a construction organization. This research shows that the administrative \& legal factor is the highest factor contributing to the construction organizations' performance in the directors, project managers, and senior engineer's model with $28 \%$. While the technical factors were found to be the highest weight in the senior engineers' model with $27 \%$. This shows the importance of the technical factor to the engineers. The developed models are validated by comparing the output to the actual data 
of organization performance. The validation of the models has satisfactory results of $85 \%, 80 \%, 90 \%$, and $85 \%$ for the directors, senior engineers, project managers, and cost engineers respectively. Due to the lack of internal organization administration information, this research does not consider the diversity of cultures present in each of these organizations. Although the validation results are satisfactory, relies solely on experts' opinion without considering any quantitative data related to organizations performance should be investigated in the future studies.

\section{References}

Abraham, G L (2002) Identification of critical success factors for construction organizations in the architectural/engineering/construction $\quad(\mathrm{a} / \mathrm{e} / \mathrm{c})$ industry.

Al-Barqawi, H and Zayed, T (2006) Assessment model of water main conditions. In, The Pipeline Division Specialty Conference, Chicago, USA.[doi: 10.1061/40854 (211) 27].

Al-Barqawi, H and Zayed, T (2008) Infrastructure management: Integrated ahp/ann model to evaluate municipal water mains' performance. Journal of Infrastructure Systems, 14(4), 305-18.

Al-Harbi, K M A-S (2001) Application of the ahp in project management. International journal of project management, 19(1), 19-27.

Al Khalil, M I (2002) Selecting the appropriate project delivery method using ahp. International journal of project management, 20(6), 469-74.

Babatunde, S. O., Perera, S., \& Zhou, L. (2016). Methodology for developing capability maturity levels for PPP stakeholder organisations using critical success factors. Construction Innovation, 16(1).

Barakat, O, Bendou, A and Martin, J C (2015) Success factors for local development project management case of taroudant province - morocco. Journal of North African Research in Business, 2015(2015).

Bevilacqua, M., Ciarapica, F. E., \& De Sanctis, I. (2017). Lean practices implementation and their relationships with operational responsiveness and company performance: an Italian study. International Journal of Production Research, 55(3), 769-794.

Böhm, E., Eggert, A., \& Thiesbrummel, C. (2017). Service transition: A viable option for manufacturing companies with deteriorating financial performance?. Industrial Marketing Management, $60,101-111$.
Boynton, A C and Zmud, R W (1984) An assessment of critical success factors. Sloan Management Review (pre-1986), 25(4), 17-27.

Connelly, B. L., Tihanyi, L., Ketchen, D. J., Carnes, C. M., \& Ferrier, W. J. (2017). Competitive repertoire complexity: Governance antecedents and performance outcomes. Strategic Management Journal, 38(5), 1151-1173.

Dang, C. N., \& Le-Hoai, L. (2016). Critical success factors for implementation process of design-build projects in Vietnam. Journal of Engineering, Design and Technology, 14(1), 17-32.

Elwakil, E, Ammar, M, Zayed, T, Mahmoud, M, Eweda, A and Mashhour, I (2009) Investigation and modeling of critical success factors in construction organizations. In, Construction Research Congress 2009@sBuilding a Sustainable Future. ASCE, 3509.

Ersoz, H (1995) 'A new approach to productivity estimation: Ahp and fuzzy set application, MSc thesis, Construction Engineering and Management Division, School of Civil Engineering, Purdue Univ., West Lafayette, Ind.

Goepel, K D (2013) Implementing the analytic hierarchy process as a standard method for multicriteria decision making in corporate enterprises-a new ahp excel template with multiple inputs. In, Proceedings of the international symposium on the analytic hierarchy process, Kuala Lumpur, Malaysia.

Holohan, J (1992) Use of executive information systems in measuring business performance. Journal of Information Technology, 7(3), 177-86.

Hu Y, Chan AP, Le Y, Xu Y, Shan M. 2016. Developing a program organization performance index for delivering construction megaprojects in China: fuzzy synthetic evaluation analysis. J. Manag. Eng. 05016007.

Kaplan, R S and Norton, D P (1995) Putting the balanced scorecard to work. Performance measurement, management, and appraisal sourcebook, 66.

Kim, H. J., \& Reinschmidt, K. F. (2011). Market structure and organizational performance of construction organizations. Journal of Management in Engineering, 28(2), 212-220.Korpela, $\mathbf{J}$ and Tuominen, M (1996) A decision aid in warehouse site selection. International Journal of Production Economics, 45(1), 169-80.

Li, J., Sun, W., Jiang, W., Yang, H., \& Zhang, L. (2017). How the Nature of Exogenous Shocks and Crises Impact Company Performance?: The Effects of Industry Characteristics. International Journal of Risk and Contingency Management (IJRCM), 6(4), 40-55. 
Lichtenthaler, U. (2016). Toward an innovation-based perspective on company performance. Management Decision, 54(1), 66-87.

Mao P, Li S, Ye K, Cai H. (2016). A field theory based model for identifying the effect of organizational structure on the formation of organizational culture in construction projects. KSCE J. Civ. Eng. 2:19.

Martinez-Conesa, I., Soto-Acosta, P., \& PalaciosManzano, M. (2017). Corporate social responsibility and its effect on innovation and firm performance: An empirical research in SMEs. Journal of Cleaner Production, 142, 2374-2383.

Müller, R., \& Jugdev, K. (2012). Critical success factors in projects: Pinto, Slevin, and Prescott-the elucidation of project success. International Journal of Managing Projects in Business, 5(4), 757-775.

Nilashi, M., Zakaria, R., Ibrahim, O., Majid, M. Z. A., Zin, R. M., \& Farahmand, M. (2015). MCPCM: a DEMATEL-ANP-based multi-criteria decisionmaking approach to evaluate the critical success factors in construction projects. Arabian Journal for Science and Engineering, 40(2), 343-361.

Ozorhon, B. (2012). Analysis of Construction Innovation Process at Project Level. Journal of Management in Engineering (October), 120915010108004. doi:10.1061/(ASCE)ME.19435479.0000157Pinto, J. K., \& Covin, J. G. (1989). Critical factors in project implementation: a comparison of construction and R\&D projects. Technovation, 9(1), 49-62.
Rathore, Z. (2016). A framework for organizational performance assessment in the construction industry (Doctoral dissertation, Purdue University).

Rockart, J F (1978) Chief executives define their own data needs. Harvard Business Review, 57(2), 81-93.

Saaty, T L (1990) How to make a decision: The analytic hierarchy process. European journal of operational research, 48(1), 9-26.

Saaty, T L (2008) Decision making with the analytic hierarchy process. International journal of services sciences, 1(1), 83-98.

Tsiga, Z. D., Emes, M., \& Smith, A. (2016). Critical Success Factors for Projects in the Space Sector. The Journal of Modern Project Management, 3(3).

Veshosky, D. (1998). Managing Innovation Information in Engineering and Construction Firms. Journal of Management in Engineering, 14 (February), 58\{66. doi: 10.1061/(ASCE)0742-597X(1998)14:1(58)

Wibowo, A., \& Alfen, H. W. (2015). Government-led critical success factors in PPP infrastructure development. Built Environment Project and Asset Management, 5(1), 121-134.

Zayed, T, Elwakil, E and Ammar, M (2012) A framework for performance assessment of organisations in construction industry. International Journal of Architecture, Engineering and Construction, 1(4), 199-212. 


\section{Appendix 1}

A sample of survey and the collected raw data

\begin{tabular}{|c|c|c|c|}
\hline \multirow[t]{2}{*}{ Category } & \multirow[t]{2}{*}{ Success Factors } & \multicolumn{2}{|c|}{ Responses (Scale: 1-5) } \\
\hline & & Sample \#1 & Sample \#2 \\
\hline \multirow{5}{*}{$\begin{array}{l}\text { Administrative } \\
\text { and Legal }\end{array}$} & 1. Clear Vision, Mission and Goals & 5 & 5 \\
\hline & 2. Competition Strategy & 3 & 5 \\
\hline & 3. Organizational Structure & 5 & 5 \\
\hline & 4. Political Conditions & 4 & 4 \\
\hline & 5. Number of Full Time Employees & 5 & 5 \\
\hline \multirow[t]{5}{*}{ Technical } & 6. Usage of International Aspects (ISO) & 3 & 4 \\
\hline & 7. Availability of knowledge & 4 & 4 \\
\hline & 8. Usage of IT & 5 & 5 \\
\hline & 9. Business Experience (no. of years) & 4 & 4 \\
\hline & 10. Product Maintenance & 2 & 3 \\
\hline \multirow[t]{4}{*}{ Management } & 11. Employee Culture Environment & 5 & 4 \\
\hline & 12. Employee Compensation and Motivation & 5 & 4 \\
\hline & 13. Applying Total Quality Management & 3 & 4 \\
\hline & 14. Training & 3 & 4 \\
\hline \multirow[t]{4}{*}{ Market and Finance } & 15. Quick Liquid Assets & 3 & 4 \\
\hline & 16. Feedback Evaluation & 4 & 4 \\
\hline & 17. Research and Development & 5 & 5 \\
\hline & 18. Market Conditions/Customer Engagement & 5 & 5 \\
\hline \multicolumn{2}{|c|}{ Overall Company Performance $(\%)$} & 70 & 80 \\
\hline
\end{tabular}

